\title{
An Internet of Thing based Agribot (IOT- Agribot) for Precision Agriculture and Farm Monitoring
}

\author{
Kakelli Anil Kumar \\ School of Computer Science and Engineering, VIT, Vellore, TN, 632006, India \\ E-mail: anilkumar.k@vit.ac.in
}

Aju. D

School of Computer Science and Engineering, VIT, Vellore, TN, 632006, India

Received:07 April 2020; Accepted: 13 May 2020; Published: 08 August 2020

\begin{abstract}
Developing nations like India have a huge potential for agricultural business and better cultivation. Because of the large size of cultivation land, improper water supply systems and lack of technology-based agricultural practices, there is a huge gap among expected and actual quantity and quality of agricultural products. Hence there is a need for significant revival in agribusiness using emerging technologies. The article proposes an intelligent water framework device called Agribot designed for the agricultural industry to minimize the water wastage and a better supply of cultivating materials using the Internet of Things (IoT). Our proposed IOT- Agribot will energize the water framework, improve the cost-effective water usage and reduce the labor force to achieve precision agriculture. The proposed IOT- Agribot has performed well for variable weather conditions, soli type, moisture content and crops.
\end{abstract}

Index Terms: Agribot, IOT, precision agriculture, sensors

\section{Introduction}

The economic growth of most of countries has been depended on agriculture-based products, rural development and animal livelihood. The present development of the agriculture industry is internet of agriculture (IOA). IOA is aimed for increase the crop yield and minimizing the work force. In existing systems there are various kinds of Agri-bots have been proposed to achieve precision agriculture. These bots can do various functions like detect the soil moisture content, notifications to the farmers, planting, and pesticides spay. These bots have components like Arduino as the main controller, DC motors, relay, battery, servo motor, spiked wheels with well standard mechanical design to resist the real time conditions. Advancement empowered every possible thing to exchange information for better decisions and high quality of service. The single board PCs and Arduino board with DIY is designed for water framework in cultivating [1]. The water framework system is exceptionally using remote sensors and forward the data to world wide web [2]. Data in the cloud is secured and an organization server can monitor, validate the input control movement [3, 4]. Today's precision agriculture is achieved using the advanced farming technologies like wireless sensor networks, satellite technology, robotic machines/bots for auto control and accurate decision w. r. to the real time conditions, and also forwarding the real time data to cloud servers for data analysis, stock management and accurate future predictions.

\section{Literature Survey}

In sensor based automated irrigation system with internet of things (IOT) [5] has introduced the dampness of the soil and proposed a system to monitor the moisture levels of soil. In this model, a motor pump on or off state is decided by a threshold level of moisture. Pump operation state is communicated to the farmer through GSM module. The farmer receives a short message service (SMS) about the states of pump operations with the help of microcontroller and GSM module connection to MAX 232. Smart irrigation using IOT [6] has proposed a blend of equipment and programming, the model makes use of Arduino Uno R3 microcontroller. The system works on the basis of soil moisture levels. The system has sensors placed over the field and collects the sensor values transferring the data through ESP8266 WIFI module.

In smart irrigation system based on soil moisture levels using IOT [7] has proposed framework consists of Arduino based controlled irrigation system using ESP8266 WiFi Module using IOT platform. In IoT based smart crop-field monitoring and automation irrigation system [8] is introduced two sensors which are used gather the information as simple 
qualities. IC3208 changes these simple qualities to 12- bit values, advanced qualities are offered to Raspberry Pi for information transmission to database using Wi-Fi. Sensors are adjusted and the base wet condition in field is $2.4 \mathrm{v}$ taken, voltages limits are fluctuated with different yield field in different seasons. IOT based smart irrigation system [9] has proposed with 2 YL-69 soil dampness sensors alongside LM393 comparator modules were set in various soil conditions for investigation. Sensor YL-69 is comprised of two nodes from figure 5. In solar powered smart irrigation system using the internet of things [10], SSIS notwithstanding a correlative Android App has been modeled. Computerized water system framework model specifically SSIS intended to be a proficient and contrast to manual water system frameworks to minimize the wastage of water. This facilitates are managing water utilization of farming area by occasionally assessing dirt dampness, stickiness and temperature through sensors. In IOT Based smart agriculture monitoring system [11], different sensor units are deployed in the field like temperature, PIR and moisture sensors. Information gathered from those sensors are associated with the microcontroller through RS 232. In a multipurpose agricultural robot, Agribot is expected for rustic purposes expected to confine by farmers not withstanding developing pace and precision in work. This plays basic limits identified with creating for example wrinkling field, planting, covering seeds in the dirt [12]. In agricultural aid to seed cultivation [13], an agribot machine insight is making development towards various fields of structure and advancement. Intelligent robots are chomped in cultivation, it is expected to accept the power over agrarian areas and can be work in different weather conditions to improve the agro-business. In the design and operation of Wi-Fi agribot integrated system, the proposed model involves an agribot which helps to locate the position of the seeds planted. This model uses an Arduino board embedded with ATMEGA 328 microcontroller [14] shown in figure 7.

\section{Proposed Advanced IOT based Agribot}

In our proposed model, the soil sogginess and temperature are evaluated using sensing devices at the field. Data is sent to the cloud by ESP 8266 Wi-Fi module [15] as shown in Fig. 1.

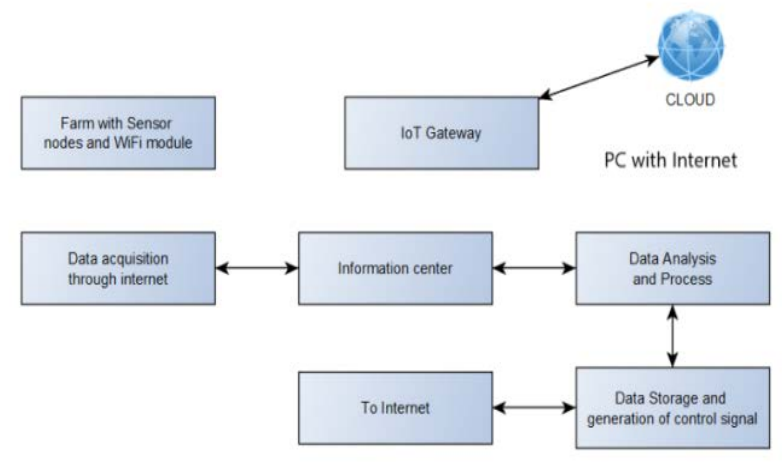

Fig. 1. Proposed IOT-Agribot model

\subsection{Design of IOT-Agribot}

1. Robot module consists of an Arduino Uno R3 Atmega 328P (5V) board to integrates all functional components.

2. The ultrasonic sensor is used to control the moment of the robot by avoiding the obstacles.

3. The robot stops for every 10 seconds in its journey to collect the values of moisture, temperature, and humidity and updates it to the cloud.

4. Motor drivers L293D are installed to drive the agribot as shown in figure 6 .

5. Agribot is controlled using Bluetooth module 8293D.

6. Agribot is powered by solar energy.

\subsection{Design Model of Sensor Module}

1. All sensing hub consists of sensors, Arduino is utilized to gather sensor information.

2. The soil moisture sensor is used to read the soil moisture values from the crop shown in figure 5 .

3. DHT 11 sensor is used to collect temperature and humidity values from the crop.

4. Arduino is utilized to gather sensor information.

5. Wi-Fi availability is given to sensing hub utilizing ESP 8266 module.

6. Arduino sends gathered information to administration servers by means of the Wi-Fi network by IoT portal.

7. The cloud services.

\subsection{Pump Operation model}

1. The pump operation time is defined based on the moisture contents in the soil as shown in figure 2.

2. If the soil moisture exceeds the threshold value, then the pump motor is to turn off state.

3. If the threshold value is not detected, then threshold values of temperature and humidity are checked and if the 
threshold conditions are not reached then the pump operation time is defined and the time is given as delay to the relay and the pump motor is turned off for defined time interval.

4. If the threshold conditions are met, then the system remains in the tuned off state, and the agribot continuously monitors the moisture levels throughout the crop field.

5. Graphical representation of incurred results.

\subsection{Hardware}

Equipment utilized for creating the proposed framework. ESP-8266 is Wi-Fi module used to interface the sensor to cloud shown in figure 4. DHT-11 for mugginess of soil. 12V DC pump utilized for water supply at any location water content falls below the threshold point as shown figure 3.

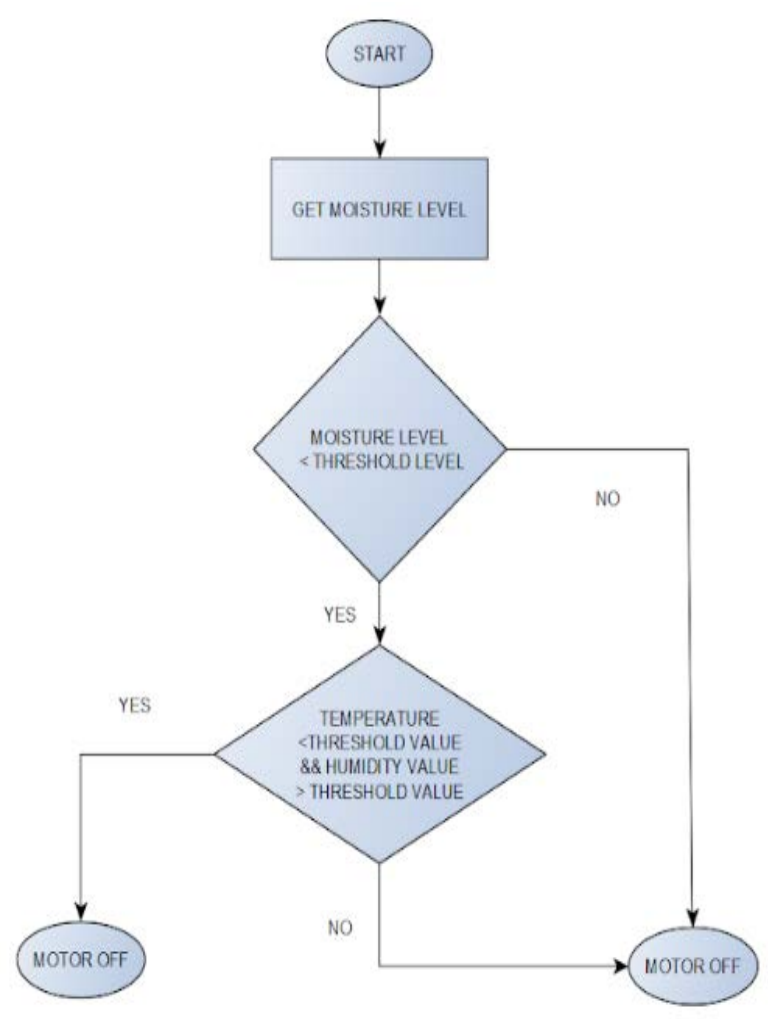

Fig. 2. Water pump operation model using IOT-Agribot

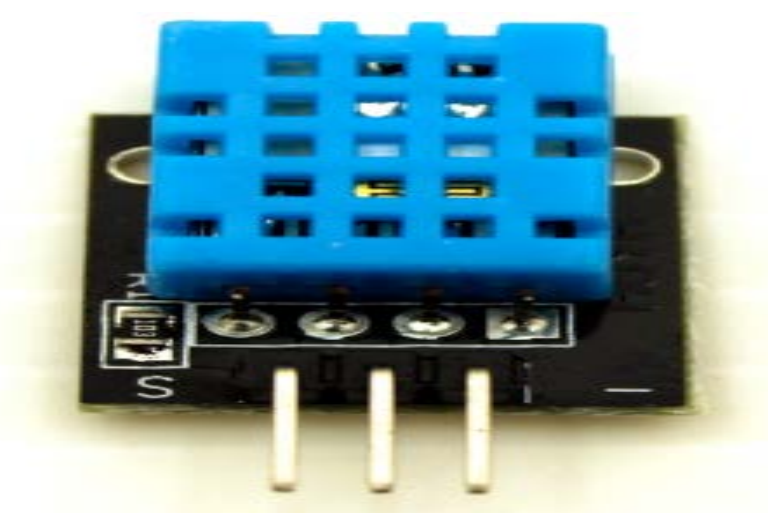

Fig. 3. DHT 11 Temperature and Humidity Sensor of IOT-Agribot

\section{Results and Analysis}

The developed system is a fully automated agriculture system for efficient resource management, and solar-powered robot harnesses solar energy instead of fuel-based irrigation as shown in figures 8 and 9. 


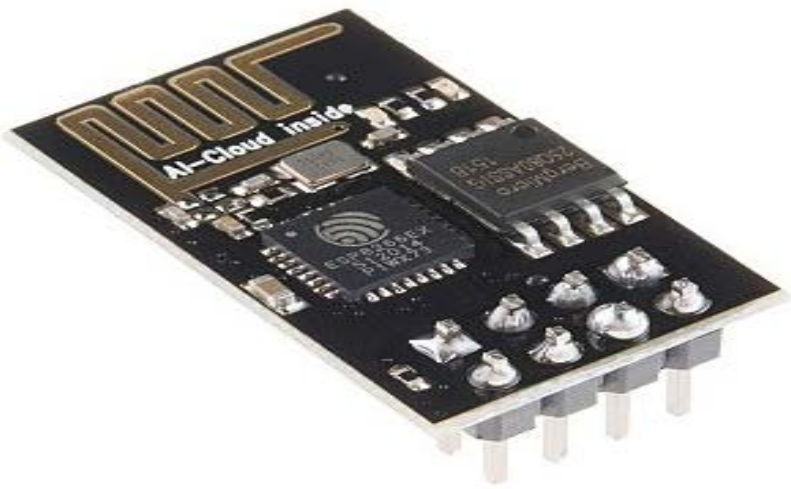

Fig. 4. ESP8266 WIFI module of IOT-Agribot

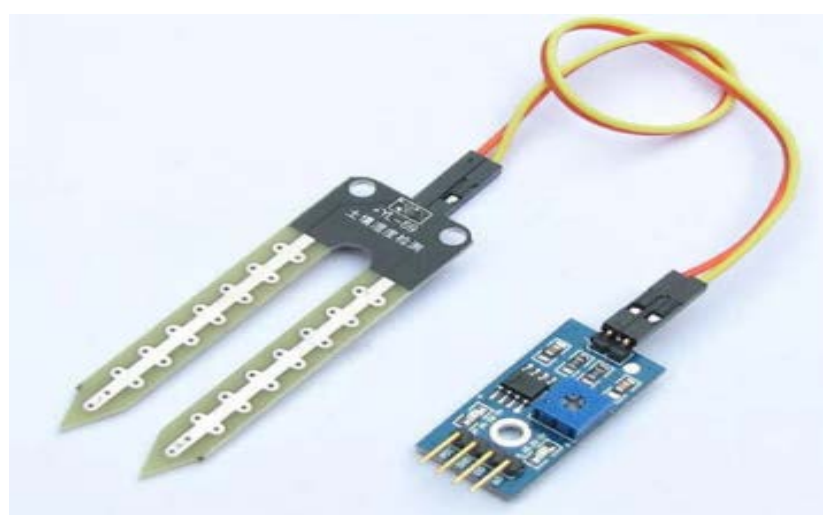

Fig. 5. Soil moisture sensor of IOT-Agribot

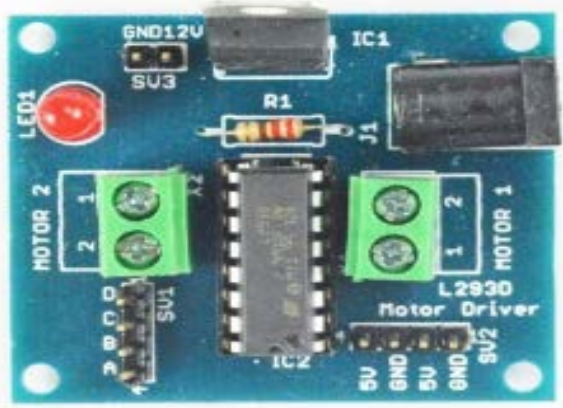

Fig. 6. L293D Motor driver of IOT-Agribot

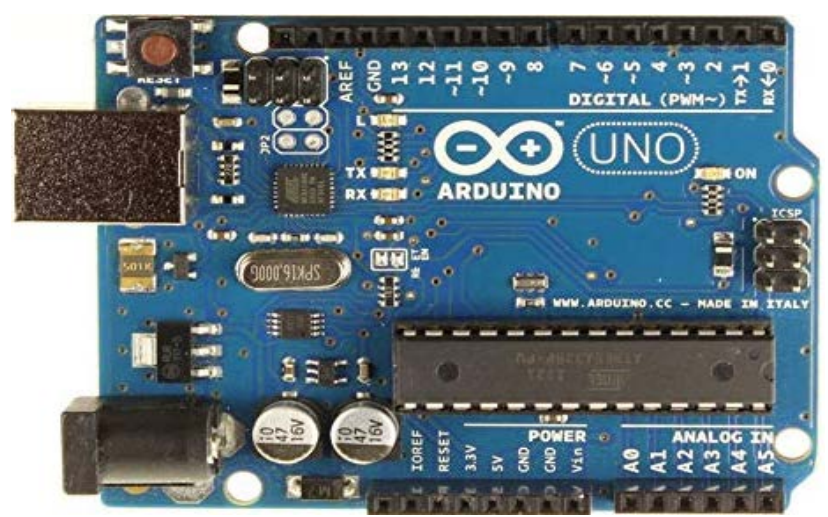

Fig. 7. Arduino UNO R3 microcontroller of IOT-Agribot 
The robot module consists of various components including the two-arm robot, Arduino board, ultrasonic sensor, solar panel, relay circuit, and a Bluetooth module. Arduino microcontroller is used as a prime controller to make the entire functioning of the robot possible. The robot is a two-way controlled: automatic and Bluetooth controlled. An ultrasonic sensor is placed at the head of the robot to sense the obstacles. The sensor module is the main hub of the Agribot. This model consists of an Arduino board integrated with a number of sensors includes soil moisture sensor, DHT11 (temperature and humidity sensor), gas sensor, and a motor.

The sensors are continuously collecting the data and update the readings to the cloud. The predefined threshold value for the soil moisture according to the crop and the type of farmland. Whenever the soil moisture is less than the threshold, the pump operation time required for setting the moisture levels to the threshold is displayed at the console. The motor turns on automatically for the said amount of time without human intervention. The sensor module from the equation 1 supplies a sufficient amount of water automatically without manpower. The equation 1 for the pump operation time (POT) is set as follows with threshold value (TV), soil moisture value (SMV) and motor pump rate (MPR).

$$
\mathrm{POT}=(\mathrm{TV}-\mathrm{SMV}) / \mathrm{MPR}
$$

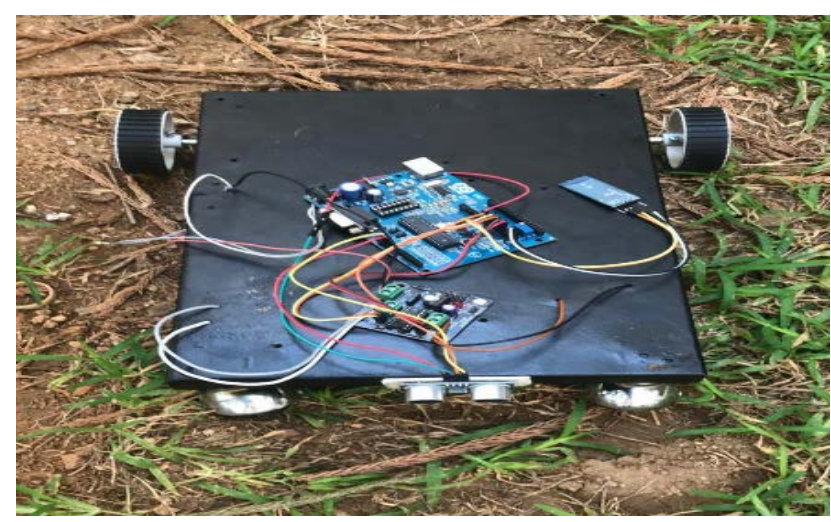

Fig 8. Deployment of IOT-Agribot for real time data collection

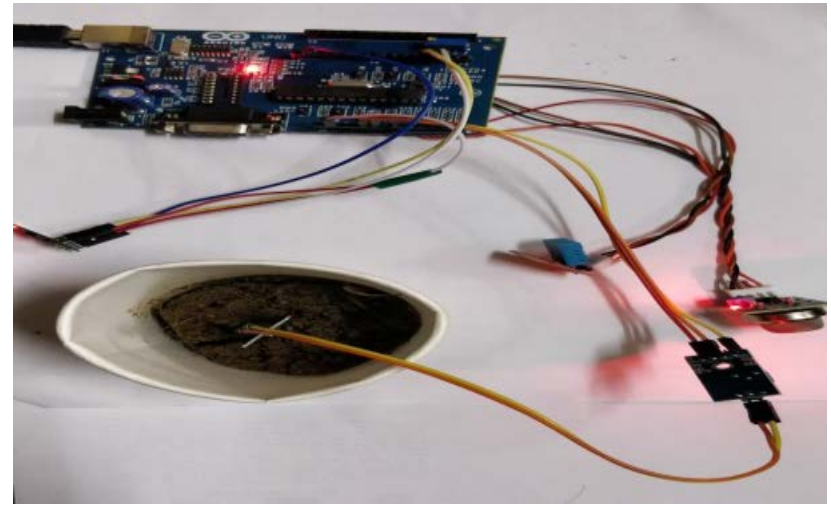

Fig.9. IOT-Agribot Sensor module consists of gas, DHT, moisture

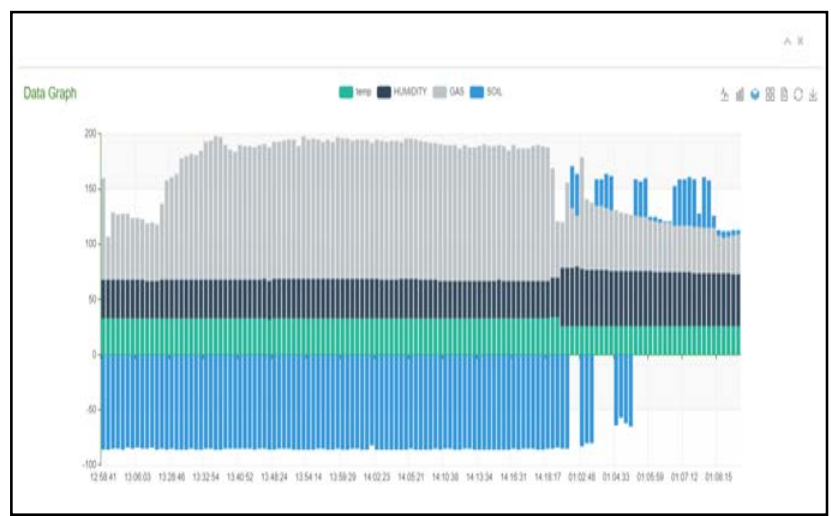

Fig. 10. Gas, Humidity, and Temperature values from Agribot to Cloud Server

The results are including the pump operation time based on moisture, humidity levels in graphical representation. The raw data is continuously updated to the cloud and can be used for further analysis from figures 10 and 11 . The raw data at 
the cloud server is represented in the form of graphs. The graphs were plotted between time on the $\mathrm{x}$-axis against the soil moisture, temperature, humidity and gas values on the y-axis. In the given case, the soil moisture is far less than the threshold value. The pump rate is calculated accordingly, and the motor turns on based on the estimated time. The estimated time is given as delay to the agribot. In the second case, the soil moisture is less than the threshold value. The pump rate is calculated to turn on the motor based on the estimated time. The estimated time is given as delay to the agribot and the values will be updated in the cloud.

In the third case, the soil moisture is greater than the predefined threshold value. Hence, the pump does not turn on, and the same is displayed on the console. The agribot move on to the field until the next stop. The data will be updated to the cloud. Table 1 shows the results (raw data) received on April 2nd 2019 from 12.58 pm to 02.30 pm from the proposed IOT agribot system and same have been observed in figure 11.

Table 1. The raw data results received from IOT agribot

\begin{tabular}{|c|c|c|c|c|c|}
\hline S. No & $\begin{array}{l}\text { temp } \\
\text { (C) }\end{array}$ & $\begin{array}{c}\text { humid } \\
\text { ity } \\
(\%)\end{array}$ & $\begin{array}{l}\text { gas } \\
\text { (pc) }\end{array}$ & $\begin{array}{c}\text { soil } \\
\text { moist }\end{array}$ & $\begin{array}{l}\text { Time } \\
(\mathrm{pm})\end{array}$ \\
\hline 1 & 33 & 70 & 92 & 86.19 & 12.58 \\
\hline 2 & 33 & 70 & 31 & 86.26 & 1.04 \\
\hline 3 & 33 & 70 & 69 & 86.22 & 1.04 \\
\hline 4 & 33 & 70 & 59 & 86.54 & 1.04 \\
\hline 5 & 33 & 70 & 60 & 86.37 & 1.04 \\
\hline 6 & 33 & 70 & 60 & 84.11 & 1.05 \\
\hline 7 & 33 & 70 & 56 & 86.59 & 1.07 \\
\hline 8 & 33 & 70 & 56 & 84.73 & 1.12 \\
\hline 9 & 33 & 70 & 55 & 84.55 & 1.15 \\
\hline 10 & 33 & 68 & 52 & 84.75 & 1.18 \\
\hline 11 & 33 & 68 & 53 & 84.63 & 1.21 \\
\hline 12 & 33 & 68 & 51 & 84.52 & 1.22 \\
\hline 13 & 33 & 70 & 69 & 84.40 & 1.25 \\
\hline 14 & 33 & 70 & 90 & 84.28 & 1.32 \\
\hline 15 & 33 & 70 & 93 & 84.17 & 1.45 \\
\hline 16 & 33 & 70 & 96 & 84.05 & 1.53 \\
\hline 17 & 33 & 70 & 110 & 83.93 & 2.00 \\
\hline 18 & 33 & 70 & 112 & 83.82 & 2.03 \\
\hline 19 & 33 & 70 & 114 & 83.70 & 2.07 \\
\hline 20 & 33 & 70 & 113 & 83.58 & 2.10 \\
\hline 21 & 33 & 70 & 117 & 83.47 & 2.15 \\
\hline 22 & 33 & 70 & 125 & 83.35 & 2.22 \\
\hline 23 & 33 & 70 & 126 & 83.23 & 2.30 \\
\hline
\end{tabular}
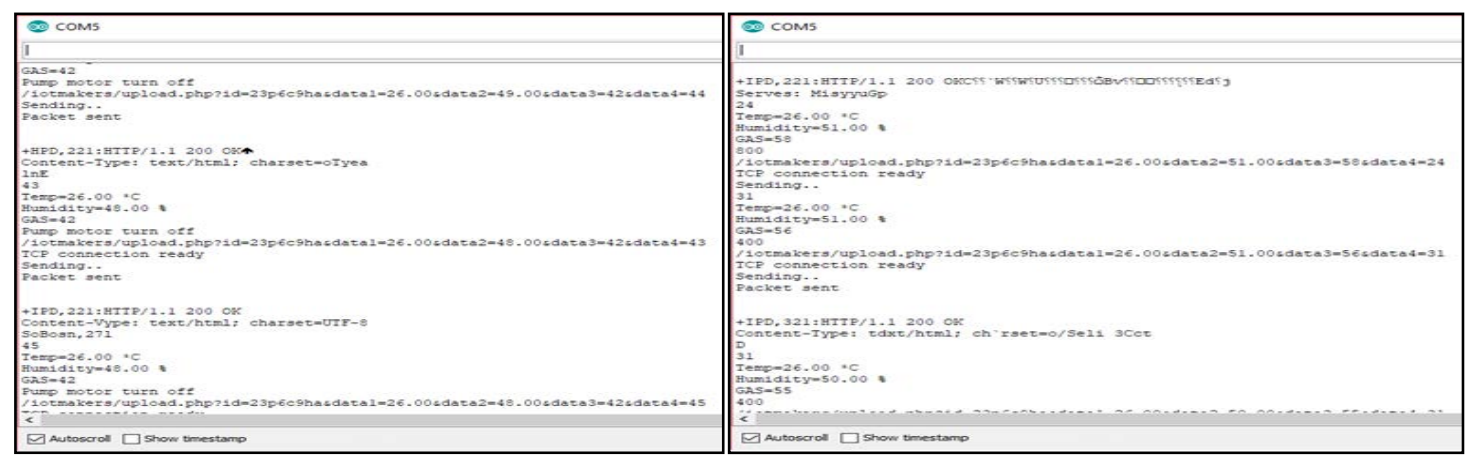

Fig. 11. IOT-Agribot Console after data analysis 


\section{References}

[1] D.S. Rahul, S.K. Sudarshan, K. Meghana, K.N. Nandan, R. Kirthana, P. Sure. IoT based solar powered Agribot for irrigation and farm monitoring: Agribot for irrigation and farm monitoring. Proceedings of the 2nd International Conference on Inventive Systems and Control, 2018, 826-831.

[2] D. Thakur, Y. Kumar, A. Kumar, P.K. Singh. Applicability of Wireless Sensor Networks in Precision Agriculture: A Review. Springer, 2019.

[3] P.J. Sarkar, S. Chanagala. A Survey on IOT based Digital Agriculture Monitoring System and Their impact on optimal utilization of Resources. IOSR Journal of Electronics and Communication Engineering, 2016 11:2278-2834.

[4] A. Rajput, V.B. Kumaravelu. Scalable and sustainable wireless sensor networks for agricultural application of Internet of things using fuzzy c-means algorithm. Sustainable Computing: Informatics and Systems, 2019 22:62-74.

[5] K. Kansara, V. Zaveri, S. Shah, S. Delwadkar, K. Jani, Sensor based automated irrigation system with IOT: A technical review. Int. J. Comp. Sci. Inf. Tech, 2015, 6: 5331-5333.

[6] A. Gori, M. Singh, O. Thanawala, A. Vishwakarma, A. Shaikh. Smart Irrigation System using IOT. International Journal of Advanced Research in Computer and Communication Engineering, 2007, 3297:213-216.

[7] S. Thakare, P.H. Bhagat. Arduino-Based Smart Irrigation Using Sensors and ESP8266 WiFi Module. Proceedings of the 2nd International Conference on Intelligent Computing and Control Systems, 2019, 1085-1089.

[8] R. Nageswara Rao, B. Sridhar. IoT based smart crop-field monitoring and automation irrigation system. Proceedings of the 2nd International Conference on Inventive Systems and Control, 2018, 478-483.

[9] S. Rawal. IOT based Smart Irrigation System. International Journal of Computer Applications, 2017, 159:7-11.

[10] K.K. Rout, S. Mallick, S. Mishra. Solar Powered Smart Irrigation System Using Internet of Things. Proceedings of 2nd International Conference on Data Science and Business Analytics, 2018, 144-149.

[11] N. Suma, S.R. Samson, S. Saranya, G. Shanmugapriya, R. Subhashri, IOT Based Smart Agriculture Monitoring System, International Journal on Recent and Innovation Trends in Computing and Communication, 2017, 2:177-181.

[12] A. Gollakota, M.B. Srinivas. Agribot - A multipurpose agricultural robot. Proceedings - 2011 Annual IEEE India Conference: Engineering Sustainable Solution, 2011, 1-4.

[13] T. Choudhury, A. Kaur, U.S. Verma. Agricultural aid to seed cultivation: An Agribot. Proceeding of IEEE International Conference on Computing, Communication and Automation, 2017, 993-998.

[14] G. Amer, S.M.M. Mudassir, M.A. Malik. Design and operation of Wi-Fi agribot integrated system. International Conference on Industrial Instrumentation and Control, 2015, 207-212.

[15] L. Syafa'Ah, A.E. Minarno, F.D.S. Sumadi, D.A.P. Rahayu. ESP 8266 for Control and Monitoring in Smart Home Application. Proceedings 2019 International Conference on Computer Science, Information Technology, and Electrical Engineering, 2019, $1: 123-128$

\section{Authors' Profiles}

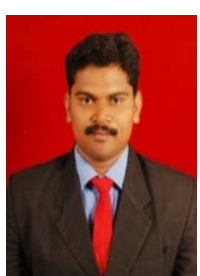

Dr. Kakelli Anil Kumar working as Associate Professor at the School of Computer Science and Engineering (SCOPE), Vellore Institute of Technology, Vellore, Tamil Nadu, India. He received the M. Tech (Software Engineering) and Ph.D. (Computer Science and Engineering) degrees from Jawaharlal Nehru Technological University Hyderabad, in 2009 and 2017, respectively. He has published more than 30 research articles in reputed international peer-reviewed journals and conferences. And, he has served as reviewer for few international peerreviewed journals. He is having more than 16 years of teaching and research experience. His research interests are Secure Protocol Design in IOT and Wireless Sensor Networks, Secure Cloud Computing Services, Block-chain and Crypto-currency and Digital Forensics. He has published over 25 research articles in reputed international journals and conferences.

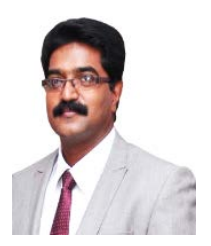

Dr. Aju. D received his PhD. in Computer Science and Engineering from VIT University, Vellore, India. He received his M.Tech. degree in Computer Science and IT from Manonmaniam Sundaranar University, Tirunelveli. He received his M.C.A degree from Madras University, India. Presently, he is working as Associate Professor at VIT University in the department of Computer Science and Engineering. He has published 30 research articles in different reputed international peer-reviewed journals. And, he has served as reviewer for few international peerreviewed journals. He is having more than 15 years of teaching and research experience. Consecutively, he has received research awards from 2014 to 2019 for his outstanding contribution towards research and publication at VIT University. His area of interest includes Digital Image Processing, Medical Imaging, Computer Graphics, Multimedia Systems and Digital Forensics.

How to cite this paper: Kakelli Anil Kumar, Aju. D., " An Internet of Thing based Agribot (IOT- Agribot) for Precision Agriculture and Farm Monitoring ", International Journal of Education and Management Engineering (IJEME), Vol.10, No.4, pp.33-39, 2020. DOI: $10.5815 /$ ijeme.2020.04.04 